\title{
PENGARUH LINGKUNGAN KERJA DAN FASILITAS TERHADAP LOYALITAS KARYAWAN PT. TELEVISI TRANSFORMASI INDONESIA
}

\author{
Reza Suriansha \\ STIE Unisadhuguna Jakarta, Indonesia \\ Email : reza@ubs-usg.ac.id
}

\begin{abstract}
Abstrak
Pendahuluan : Kinerja pada dasarnya adalah apa yang dilakukan atau yang tidak dilakukan karyawan untuk mengatasi hal-hal tersebut. pihak pimpinan suatu instansi pemerintah memerlukan adanya upaya-upaya menyeluruh untuk meningkatkan motivasi kerja yang tinggi, yang nantinya diharapkan tugas-tugas yang dibebankan kepada setiap pegawai dapat berjalan sebagaimana yang diharapkan.

Tujuan : Penelitian ini bertujuan untuk meneliti dan menganalisis pengaruh lingkungan kerja dan fasilitas terhadap loyalitas karyawan PT Television Transformation of Indonesia. Data yang dikumpulkan melalui distribusi kuesioner dan diimplementasikan kepada PT Television Transformasi Indonesia 85 karyawan. Analisis data dalam penelitian ini menggunakan bantuan SPSS versi 22. Penelitian ini dilakukan selama periode Juli 2017 - Oktober 2017.

Metode : Teknik analisis yang digunakan adalah regresi berganda. Ini juga menguji uji validitas, analisis regresi, dan assumtions klasik yang mencakup tes normalitas, tes multikolinearitas, dan tes heteroscedasticity.

Hasil : Hasilnya penelitian ini tidak menemukan variabel yang menyimpang dari assumtions klasik, ini menunjukkan bahwa data yang tersedia telah memenuhi syarat untuk menggunakan model persamaan regresi linier berganda. Dari hasil penelitian menunjukkan bahwa gaya kepemimpinan variabel dan motivasi sebagian postivie secara signifikan. Kemampuan prediktif dari dua variabel pada karyawan kinerja sebesar 70,5\%.

Kesimpulan : Hasil pengujian dan analisis atas hipotesis bahwa Lingkungan Kerja mempengaruhi secara parsial terhadap Loyalitas Karyawan PT. Televisi Transformasi Indonesia, dapat dibuktikan berpengaruh ariable signifikan.
\end{abstract}

Kata kunci : Lingkungan Kerja; Fasilitas dan Loyalitas Karyawan.

\section{Abstract}

Introduction: Performance is basically what employees do or don't do to address those things. The leadership of a government agency requires thorough efforts to increase high work motivation, which later it is expected that the tasks assigned to each employee can run as expected.

Objective: This research aims to research and analyze the influence of the work environment and facilities on employee loyalty of PT Television Transformation of Indonesia. Data collected through questionnaire distribution and implemented to PT Television Transformasi Indonesia 85 employees. The data analysis in this study used the help of SPSS version 22. The study was conducted during the period July 2017 - October 2017. 
Method: The analytical technique used is multiple regression. It also tests for validity tests, regression analysis, and classic assumtions that include normality tests, multicollinearity tests, and heteroscedasticity tests.

Results: The results of this study found no variables that deviated from classical assumtions, this showed that the available data had been qualified to use multiple linear regression equation models. The results showed that variable leadership styles and motivations were significantly significant. Predictive capability of the two variables in employee performance by $70.5 \%$.

Conclusion: The results of testing and analysis of the hypothesis that the Work Environment partially affects employee loyalty. Television Transformation of Indonesia, can be proven influential.

\section{Keywords : Work Environment; Facilities and Employee Loyalty.}

\section{Pendahuluan}

Kinerja merupakan terjemahan dari bahasa inggris, work performance atau job performance tetapi dalam bahasa Inggris sering disingkat menjadi performance saja (Tri Indriyanto \& Irmawati, 2014). Dalam bahasa Indonesia sering disebut juga prestasi kerja.

Kinerja pada dasarnya adalah apa yang dilakukan atau yang tidak dilakukan karyawan untuk mengatasi hal-hal tersebut (Safitri, Manajemen, \& Ekonomi, 2013), pihak pimpinan suatu instansi pemerintah memerlukan adanya upaya-upaya menyeluruh untuk meningkatkan motivasi kerja yang tinggi, yang nantinya diharapkan tugas-tugas yang dibebankan kepada setiap pegawai dapat berjalan sebagaimana yang diharapkan (Zulkarnaen, Fitriani, \& Widia, 2018). Menurut (Sofyan, 2013) peningkatan kesadaran akan kinerja, efiesiensi, efektivitas, kewirausahaan dan etos kerja produktif dilaksanakan melalui berbagai kegiatan seperti peningkatan semangat kerja, penyuluhan, pendidikan dan pelatihan dalam rangka meningkatkan kesejahteraan tenaga kerja dan kualitas tenaga kerja berdasarkan ketenagakerjaan nasional yang harus terus disempurnakan secara terarah, terpadu, dan menyeluh. Setiap orang yang berada di dunia kerja selalu memiliki impian atauharapan dari yang paling tinggi sampai yang standar saja (Sodiq, 2015) (Pandipa, 2020).

Namun dalam realita seringkali ditemukan hal-hal yang tidak mengantarkan pada harapan atau hal-hal yang diluar harapan sampai yang tidak diharapkan. Motivasi awal orang mulai bekerja pasti tidak dipungkiri karena menginginkan mendapatkan penghasilan (Taruh, 2020), artinya bahwa gaji atau upah menjadi motivasi pertama. Seiring berjalannya waktu mulailah orang mengharapkan hal-hal yang lain diluar penghasilan, seperti jaminan keselamatan kerja, jaminan kesehatan, jaminan hari tua, fasilitas transportasi, bonus, tunjangan hari raya, fasilitas fisik, lingkungan kerja, dan masih banyak lagi (Sudaryo, Aribowo, \& Sofiati, 2018). Semua itu merupakan faktorfaktor atau variabel yang mempengaruhi semangat atau motivasi kerja, produktivitas, kinerja hingga loyalitas karyawan. Lingkungan kerja merupakan faktor lain yang dapat mempengaruhi kepuasa kerja, dimana lingkungan kerja merupakan potret realitas keadaan di dunia kerjayang terus berkembang (Ichsan, 2011) (Siagian \& Khair, 2018), 
serta ditempat kerja dapat memberikan gambar mengenai hari ke hari kehidupan karyawan yang datang untuk bekerja, dating bersama-sama untuk tujuan yang sama, melaksanakan pekerjaan mereka, dan hidup dalam kerangka aturan dan peraturan perusahaan (Bhattacharya \& Mukherjee, 2012).Lingkungan kerja yang kondusif, dan nyaman berakibat langsung meningkatnya kepuasan kerja seorang karyawan (Bachtiar, 2012).

\section{Metode Penelitian}

Metode yang digunakan didalam penelitian ini adalah metode deskriptif kuantitatif (Sugiyono, 2017). Metode kuantitatif adalah ilmu dan seni yang berkaitan dengan tata cara (metode) pengumpulan data, Analisa data, dan interpretasi hasil analisis untuk mendapatkan informasi guna penarikan kesimpulan dan pengambilan keputusan (Zein et al., 2019). Penelitian ini akan melakukan survey dengan menggunakan alat kuesioner sebagai instrument pengumpulan data dan hasil itulah akan diolah dengan software SPSS versi 22 (Juliandi, Manurung, \& Satriawan, 2018).

\section{Hasil dan Pembahasan}

\section{A. Uji Validitas}

Berdasarkan table di bawah ini, dapat dilihat bahwa untuk masing-masing pertanyaan pada variable Lingkungan Kerja (X1) tidak seluruh instrument dapat dikatakan valid, karena nilai rhitung yang dihasilkan jauh lebih besar dari nilai rtabel yang ada untuk $\mathrm{n}=85$ (delapan puluh lima) yaitu 0,213.

\section{Tabel 1 Uji Validitas Variabel Lingkungan Kerja (X1)}

\begin{tabular}{|c|c|c|c|}
\hline \multirow[b]{2}{*}{ Pernyataan } & \multicolumn{3}{|c|}{ Lingkungan Kerja $\left(\mathrm{X}_{1}\right)$} \\
\hline & r Hitung & $\mathbf{r}$ Tabel $\mathbf{n}=85$ & Keterangan \\
\hline 1 & 0,276 & 0,213 & VALID \\
\hline 2 & 0,423 & 0,213 & VALID \\
\hline 3 & 0,250 & 0,213 & VALID \\
\hline 4 & 0,395 & 0,213 & VALID \\
\hline 5 & 0,319 & 0,213 & VALID \\
\hline 6 & 0,280 & 0,213 & VALID \\
\hline 7 & 0,228 & 0,213 & VALID \\
\hline 8 & 0,417 & 0,213 & VALID \\
\hline 9 & 0,334 & 0,213 & VALID \\
\hline 10 & 0,395 & 0,213 & VALID \\
\hline 11 & 0,265 & 0,213 & VALID \\
\hline 12 & 0,340 & 0,213 & VALID \\
\hline 13 & 0,135 & 0,213 & TIDAK VALID \\
\hline 14 & 0,111 & 0,213 & TIDAK VALID \\
\hline 15 & 0,239 & 0,213 & VALID \\
\hline 16 & 0,199 & 0,213 & TIDAK VAIID \\
\hline 17 & 0,121 & 0,213 & TIDAK VALID \\
\hline 18 & 0,142 & 0,213 & TIDAK VALID \\
\hline 19 & 0,420 & 0,213 & TIDAK VAIID \\
\hline 20 & 0,261 & 0,213 & VALID \\
\hline 21 & 0,287 & 0,213 & VALID \\
\hline 22 & 0,369 & 0,213 & VALID \\
\hline 23 & 0,455 & 0,213 & VALID \\
\hline 24 & 0,300 & 0,213 & VALID \\
\hline 25 & 0,437 & 0,213 & VALID \\
\hline
\end{tabular}


Tabel 2 Uji Validitas Variabel Fasilitas (X2)

\begin{tabular}{|l|l|l|l|}
\hline \multirow{2}{*}{ Pernyataan } & \multicolumn{3}{|l|}{ Fasilitas (X2) } \\
\cline { 2 - 4 } & r Hitung & r Tabel $\mathbf{n}=85$ & Keterangan \\
\hline 1 & 0,724 & 0,213 & VALID \\
\hline 2 & 0,603 & 0,213 & VALID \\
\hline 3 & 0,691 & 0,213 & VALID \\
\hline 4 & 0,725 & 0,213 & VALID \\
\hline 5 & 0,620 & 0,213 & VALID \\
\hline 6 & 0,454 & 0,213 & VALID \\
\hline
\end{tabular}

Berdasarkan table 2, dapat dilihat bahwa untuk masing-masing pernyataan pada variable Fasilitas Kerja (X2) seluruh instrument dapat dikatakan valid, karena nilai rhitung yang dihasilkan jauh lebih besar dari pada nilai rtabel yang ada untuk $n$ $=85$ (delapan puluh lima) yaitu 0,213 .

Tabel 3 Uji Validitas Variabel Loyalitas Karyawan (Y)

\begin{tabular}{|l|l|l|l|}
\hline \multirow{2}{*}{ Pernyataan } & \multicolumn{3}{|l|}{ Loyalitas Karyawan ( $\mathrm{l}$} \\
\cline { 2 - 4 } & r Hitung & r Tabel $\mathbf{n}=85$ & Keterangan \\
\hline 1 & 0,878 & 0,213 & VALID \\
\hline 2 & 0,894 & 0,213 & VALID \\
\hline 3 & 0,769 & 0,213 & VALID \\
\hline 4 & 0,828 & 0,213 & VALID \\
\hline 5 & 0,830 & 0,213 & VALID \\
\hline
\end{tabular}

Sumber: Hasil Olahan Data (SPSS 20)

Berdasarkan tabel diatas, dapat dilihat bahwa untuk masing-masing pernyataan pada variable Failitas Kerja (Y) seluruh instrument dapat dikatakan valid, karena nilai rhitung yang dihasilkan jauh lebih besar daripada nilai rtabel yang ada untuk $n=85$ (delapan puluh lima) yaitu 0,213.

\section{B. Uji Reliabilitas}

Tabel 4 Kriteria Tingkat Reliabilitas

\begin{tabular}{|c|l|l|}
\hline No. & \multicolumn{1}{|c|}{ Interval } & \multicolumn{1}{|c|}{ Kriteria } \\
\hline 1. & $<0,200$ & Sangat Rendah \\
\hline 2. & $0,200-0,399$ & Rendah \\
\hline 3. & $0,400-0,599$ & Cukup \\
\hline 4. & $0,600-0,799$ & Tinggi \\
\hline 5. & $0,800-1,000$ & Sangat Tingi \\
\hline
\end{tabular}

Tabel 5 Hasil Uji Reliabilitas Variabel (X1) Reliability Statistics

\begin{tabular}{|r|r|}
\hline $\begin{array}{l}\text { Cronbach's } \\
\text { Alpha }\end{array}$ & N of Items \\
\hline .558 & 23 \\
\hline
\end{tabular}

Sumber: Hasil Olahan Data (SPSS 20) 
Berdasarkan tabel diatas untuk uji reliabilitas variable Lingkungan Kerja (X1) dengan nilai Cronbach's Alpha sebesar 0,558, sehingga dapat disimpulkan instrument penelitian mengenai variable Lingkungan Kerja (X1) adalah Reliabel dengan kriteria sangat tinggi.

\section{Tabel 6 Hasil Uji Reliabilitas Variabel (X2) Reliability Statistics}

\begin{tabular}{|r|r|}
\hline $\begin{array}{c}\text { Cronbach's } \\
\text { Alpha }\end{array}$ & N of Items \\
\hline .822 & 6 \\
\hline
\end{tabular}

Sumber: Hasil Olahan Data (SPSS 20)

Berdasarkan variable diatas, untuk uji reliabilitas variable Fasilitas Kerja (X2) dengan nilai Cornbach's Alpha sebesar 0,822, sehingga dapat disimpulkan bahwa instrument penelitian mengenai variable Fasilitas Kerja (X2) adalah Reliabel dengan kriteria sangat tinggi.

\section{Tabel 7 Hasil Uji Reliabilitas Variabel (Y) Reliability Statistics

\begin{tabular}{|r|r|}
\hline $\begin{array}{c}\text { Cronbach's } \\
\text { Alpha }\end{array}$ & N of Items \\
\hline \multicolumn{2}{|c|}{ S98 } \\
\hline
\end{tabular}

Berdasarkan aria diatas, untuk uji reliabilitas variable Loyalitas Karyawan (Y) dengan nilai Cornbach's Alpha sebesar 0,898, sehingga dapat disimpulkan bahwa instrument penelitian mengenai variable Loyalitas Karyawan (Y) adalah Reliabel dengan kriteria sangat tinggi.

\section{Uji Asumsi Klasik}

Tabel 8

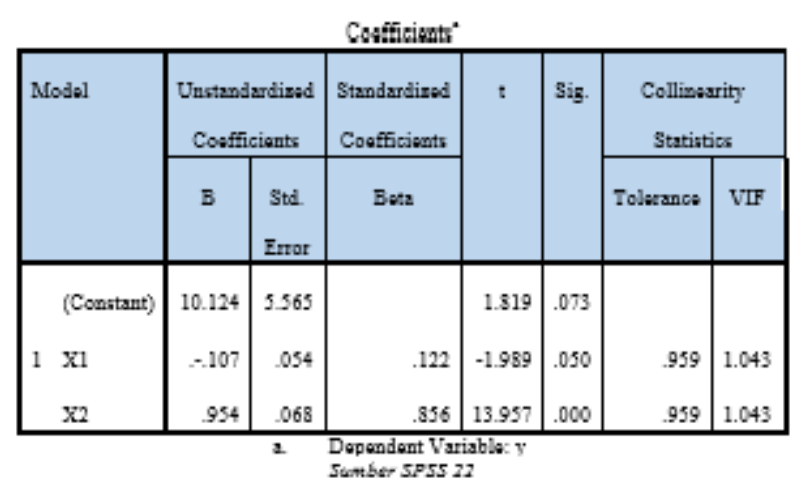




\section{Uji Normalitas}

Tabel 9 Hasil Uji Normalitas

One-Sample Kolmogorov-Smirnov Test

\begin{tabular}{|ll|r|}
\hline & & \multicolumn{1}{|c|}{$\begin{array}{c}\text { Standardized } \\
\text { Residual }\end{array}$} \\
\hline $\mathrm{N}$ & Mean & 85 \\
Normal & Std. & .0000000 \\
Parameters & & .00 \\
& Deviation & .98802352 \\
Most Extreme & Absolute & .094 \\
Differences & Positive & .094 \\
& Negative & -.052 \\
Test Statistic & & .094 \\
Asymp. Sig. (2-tailed) & $.062^{\circ}$ \\
\hline
\end{tabular}

a. Test distribution is Normal. b. Calculated from data

\section{E. Uji Multikolinieritas}

Tabel 10 Hasil Uji Multikolineritas

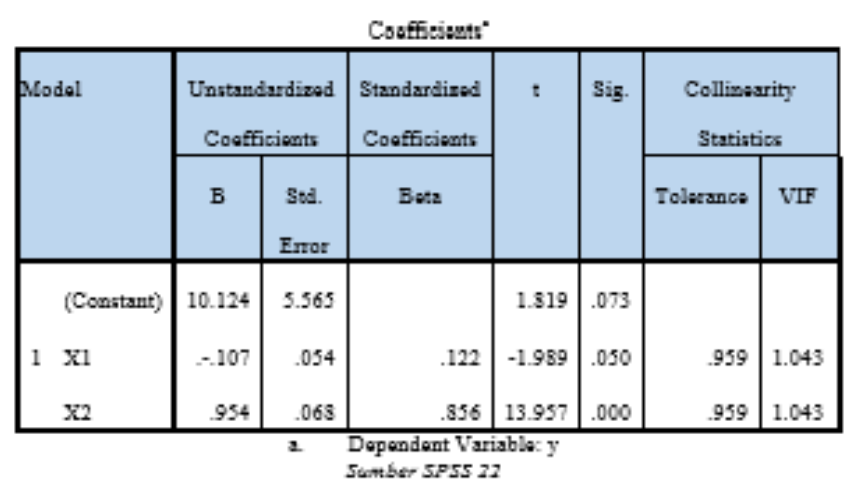

Uji Persamaan Regresi Linier Berganda

Tabel 11 Regresi Linear Berganda (Multiple)

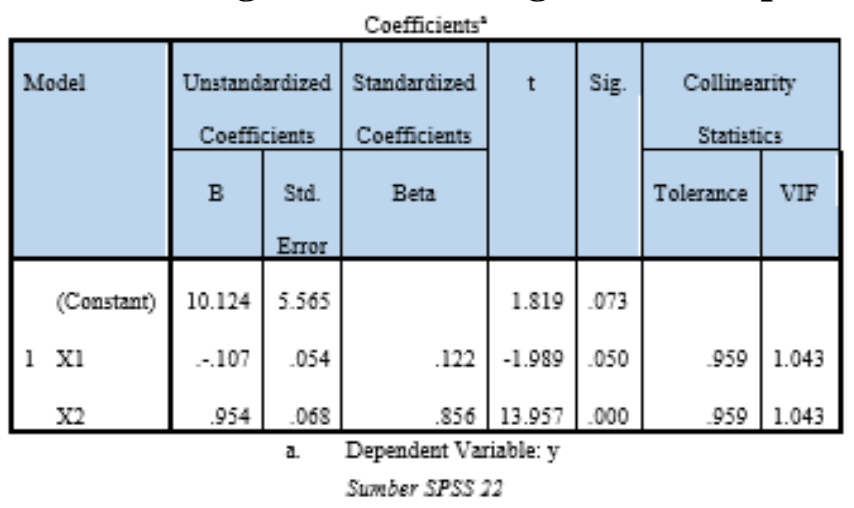

Untuk menentukan nilai persamaan regresi linear bergandanya sebagai berikut:

$\mathrm{Y}=10,124-0,107 \mathrm{X} 1+0,954 \mathrm{X} 2$. Dapat dijelaskan sebagai berikut:

1. Jika nilai konstanta sebesar 1 satuan dengan asumsi ariable Lingkungan

Kerja (X1) dan ariable Fasilitas Kerja (X2) tetap, maka nilai ariable

Loyalitas Karyawan (Y) akan naik sebesar 10,124. 
2. Nilai koefisien regresi ariable Lingkungan Kerja (X1) terhadap variable Loyalitas Karyawan (Y) adalah sebesar -0,107. Hal ini berarti jika ariable Lingkungan Kerja (X1) naik 1 satuan akan meningkatkan variable Loyalitas Karyawan (Y) sebesar -0,107, dengan asumsi ariable Fasilitas Kerja (X2) dan konstanta tidak berubah.

3. Nilai koefisien regresi ariable Fasilitas Kerja (X2) terhadap variable Loyalitas Karyawan (Y) adalah sebesar 0,954.

Hal ini berarti jika ariable Fasilitas Kerja (X2) naik 1 satuan akan meningkatkan ariable Loyalitas Karyawan (Y) sebesar 0,954, dengan asumsi ariable Lingkungan Kerja (X1) dan konstanta tidak berubah.

\section{F. Uji t}

Hubungan Variabel Lingkungan Kerja (X1) dengan Loyalitas Karyawan (Y) Jika diperhatikan hasil aria coefficients di atas dengan menggunakan perhitungan analisis SPSS Versi 22.00, maka nilai thitung untuk variable X1 (Lingkungan Kerja) sebesar-1,989 sedangkan nilai ttabel untuk $n=85$ sebesar 1,993. Jadi $-1,989<1,993$, dapat disimpulkan bahwa secara parsial ariable Lingkungan Kerja (X1) tidak berkorelasi terhadap Loyalitas Karyawan (Y).

Hubungan Variabel Fasilitas Kerja (X2) dengan Loyalitas Karyawan (Y) Jika diperhatikan hasil aria coefficiens di atas dengan menggukanan perhitungan analisis SPSS Versi 22.00, maka nilai thitung untuk variable X2 (Fasilitas Kerja) sebesar 13,957, sedangkan nilai ttabel untuk $n=85$ sebesar 1,993. Jadi 13,957 $>$ 1,993, dapat disimpulkan bahwa secara parsial ariable Fasilitas Kerja (X2) berkorelasi terhadap Loyalitas Karyawan (Y).

\section{G. Uji Simultan (F)}

Tabel 12 Hasil Uji ANOVA (F)

\begin{tabular}{|l|r|r|r|r|r|}
\hline & \multicolumn{1}{|c|}{ ANOWA of $^{\mathrm{a}}$} & \multicolumn{1}{c|}{ Mean } & & \\
Model & Squares & df & \multicolumn{1}{|c|}{ Square } & $\mathrm{F}$ & Sig. \\
\hline 1 Regression & 666.287 & 2 & 333.143 & 97.770 & $.000^{\mathrm{b}}$ \\
Residual & 279.408 & 82 & 3.407 & & \\
Total & 945.694 & 84 & & & \\
\hline
\end{tabular}

a. Dependent Variable: y $\quad$ b. Predictors: (Constant), X2, X1

Sumber: Hasil Olahan Data (SPSS 22)

Dari hasil uji ANOVA atau fhitung didapat nilai fhitung sebesar 97,770 dimana lebih besar dari nilai ftabel untuk $n=85$ sebesar 3.11 atau 97,770 > 3.11 dengan tingkat signifikan sebesar 0,000 karena $0,000<0,05$, maka dapat dikatakan Lingkungan Kerja (X1) dan Fasilitas Kerja (X2) secara simultan mampu menjelaskan Loyalitas Karyawan (Y) pada $a=5 \%$. 
Tabel 13

Model Summaryb

\begin{tabular}{|c|c|c|c|c|}
\hline M & $\mathrm{R}$ & $\begin{array}{c}\mathrm{R} \\
\text { Square }\end{array}$ & $\begin{array}{l}\text { Adjusted } \\
\text { R Square }\end{array}$ & $\begin{array}{l}\text { Std. Error of } \\
\text { the Estimate }\end{array}$ \\
\hline 1 & $9 \mathrm{a}$ & .705 & .697 & 1.84592 \\
\hline
\end{tabular}

a. Predictors: (Constant), X2, X1

b. Dependent Variable: y

Sumber: Hasil Olahan Data (SPSS 22)

Berdasarkan pada aria tersebut di atas yakni Model Summary yang menghasilkan nila R Square sebesar 0,705, artinya bahwa Lingkungan Kerja dan Fasilitas Kerja secara ariabl-sama mampumenjelaska ariable Loyalitas Karyawan sebesar $62,3 \%$ sedangkan sisanya sebesar $37,7 \%$ adalah faktor-faktor lain yang tidak diteliti dalam penelitian ini.

\section{Kesimpulan}

Hasil pengujian dan analisis atas hipotesis bahwa Lingkungan Kerja mempengaruhi secara parsial terhadap Loyalitas Karyawan PT. Televisi Transformasi Indonesia, dapat dibuktikan berpengaruh ariable signifikan. Hal tersebut dapat dilihat dari thitung untuk ariable Lingkungan Kerja (X1) sebesar 1,989 sedangkan nilai $\mathrm{t}$ aria untuk $\mathrm{n}=85$ sebesar 1,993. Karena $-1989<1,993$, dapat disimpulkan bahwa secara parsial ariable Lingkungan Kerja (X1) berpengaruh ariable signifikan terhadap Loyalitas Karyawan (Y) pada $a=5 \%$. Hasil pengujian dan analisis atas hipotesis bahwa Fasilitas Kerja mempengaruhi secara parsial terhadap Loyalitas Karyawan PT. Televisi Transformasi Indonesia, Hal tersebut dapat dilihat dari t hitung untuk ariable Fasilitas Kerja (X2) sebesar 13,957, sedangkan nilai $\mathrm{t}$ aria untuk $\mathrm{n}=$ 85 sebesar 1,993. Karena 13,957>1,993, dapat disimpulkan bahwa secara parsial ariable Fasilitas Kerja (X2) berpengaruh positif signifikan terhadap Loyalitas Karyawan (Y) pada $a=5 \%$. Lingkungan Kerja (X1) dan Fasilitas Kerja (X2) secara simultan berpengaruh terhadap loyalitas karyawan, hal tersebut dapat dilihat dari nilai fhitung sebesar 97,770, sedangkan nilai ftabel untuk $n=85$ sebesar 3.11. Jadi 97,770 > 3.11, dapat disimpulkan bahwa Fasilitas Kerja (X1) dan Fasilitas Kerja (X2) secara simultan berpengaruh terhadap Loyalitas Karyawan (Y) pada $a=5 \%$. 


\section{DAFTAR PUSTAKA}

Bachtiar, Doni. (2012). Pengaruh motivasi dan lingkungan kerja terhadap kinerja karyawan. Management Analysis Journal, 1(1).

Bhattacharya, Swaha, \& Mukherjee, Sucharita. (2012). WORK ENVIRONMENT AND ADJUSTMENT PATTERN. Social Science International, 28(2).

Ichsan, Fauqa Nuri. (2011). Pengaruh Iklim Organisasi Dan Etos Kerja Terhadap Kinerja Kepala Madrasah Tsanawiyah Negeri Di Propinsi Sumatera Barat. Jurnal Manajemen Pendidikan, 2(2).

Juliandi, Azuar, Manurung, Saprinal, \& Satriawan, Bambang. (2018). Mengolah data penelitian bisnis dengan SPSS. Lembaga Penelitian dan Penulisan Ilmiah AQLI.

Pandipa, Abd Khalid H. S. (2020). Pentingnya Disiplin Kerja Terhadap Peningkatan Efektifitas Kerja Pegawai pada Dinas Pemberdayaan Perempuan dan Perlindungan Anak Kabupaten Poso. Jurnal Ilmiah Administratie, 10(1), 9-16.

Safitri, Erma, Manajemen, J., \& Ekonomi, F. (2013). Pengaruh pelatihan dan disiplin kerja terhadap kinerja karyawan. Jurnal Ilmiah Manajemen, 1(4), 1044-1054.

Siagian, Tomy Sun, \& Khair, Hazmanan. (2018). Pengaruh Gaya Kepemimpinan Dan Lingkungan Kerja Terhadap Kinerja Karyawan Dengan Kepuasan Kerja Sebagai Variabel Intervening. Maneggio: Jurnal Ilmiah Magister Manajemen, 1(1), 59-70.

Sodiq, Amirus. (2015). Konsep kesejahteraan dalam islam. Equilibrium, 3(2), 380-405.

Sofyan, Diana Khairani. (2013). Pengaruh lingkungan kerja terhadap kinerja kerja pegawai bappeda. Industrial Engineering Journal, 2(1).

Sudaryo, Yoyo, Aribowo, Agus, \& Sofiati, Nunung Ayu. (2018). Manajemen Sumber Daya Manusia: Kompensasi Tidak Langsung dan Lingkungan Kerja Fisik. Penerbit Andi.

Sugiyono. (2017). MetodePenelitian Kuantitatif, Kualitatif dan R\&D. Bandung: PT Alfabet. Sugiyono. (2017). MetodePenelitian Kuantitatif, Kualitatif Dan R\&D. Bandung: PT Alfabet.

Taruh, Ferdinatus. (2020). Motivasi Kerja (Meniti Suara Hati Menolak Perilaku Korupsi). Deepublish.

Tri Indriyanto, Taufik, \& Irmawati, Ir. (2014). Pengaruh Kepemimpinan, Lingkungan Kerja, dan Motivasi Kerja terhadap Kinerja Karyawan di PT. Surya Kebak Tex karanganyar. Universitas Muhammadiyah Surakarta.

Zein, S. Zein, Yasyifa, L. Yasyifa, Ghozi, R. Ghozi, Harahap, Eerwin, Badruzzaman, F. H., \& Darmawan, Deni. (2019). Pengolahan dan Analisis Data Kuantitatif Menggunakan Aplikasi SPSS. Teknologi Pembelajaran, 4(2).

Zulkarnaen, Wandy, Fitriani, Iis Dewi, \& Widia, Rini. (2018). Pengaruh Motivasi Kerja Terhadap Prestasi Kerja Karyawan Pt. Alva Karya Perkasa Bandung. Jurnal Ilmiah MEA (Manajemen, Ekonomi, \& Akuntansi), 2(1), 42-62. 